\title{
Detecção de mudanças de forma automática no entorno de reservatórios: estudo de caso - Canoas I
}

\author{
Automatic Change Detection in Reservoirs: Canoas I Study Case \\ Carlos Rodrigo Tanajura Caldeira ${ }^{1}$ \\ Maurício Galo, Nilton Nobuhiro Imai, Maria de Lourdes Bueno Trindade \\ Galo, Júlio kiyoshi Hasegawa, Amilton Amorim, Milton Hirokasu \\ Shimabukuro ${ }^{2}$ \\ Marcelo Solfa Pinto ${ }^{3}$
}

Recebido em janeiro de 2017.

Aprovado em outubro de 2018.

\begin{abstract}
RESUMO
Realizar deteç̧ões de mudanças de características da superfície da Terra é importante para a compreensão tanto da dinâmica dos fenômenos quanto para a previsão dos impactos, bem como para o apoio na tomada de decisões. Durante as últimas décadas foram desenvolvidas várias técnicas de deteç̧ão de mudanças a partir de imagens, dentre elas as baseadas em imagens de Sensoriamento Remoto. Em geral, a detecção de mudança envolve a utilização de um conjunto de dados multi-temporais, que permite a análise quantitativa do fenômeno de interesse. Uma aplicação de grande interesse destas técnicas é a detecção automática de mudanças no entorno de reservatórios, que podem ser utilizados como dados auxiliares em um sistema de monitoramento das áreas de interesse. Em um sistema desta natureza espera-se que as mudanças decorrentes da ação humana sejam detectadas, mesmo na presença de diferenças entre as cenas provenientes de mudanças nas condições atmosféricas, iluminação da cena, ângulos de visada do sensor, umidade do solo, dentre outros fatores. Considerando este contexto, este trabalho apresenta resultados da avaliação de uma abordagem de deteç̧ão de alterações baseada numa modificação aplicada à técnica RCEN (Radiometric Rotation Controlled by Nonchangeaxis). O método foi implementado e aplicado em um conjunto de imagens ortorretificadas obtidas pelo sistema orbital SPOT 6, tomadas em duas épocas distintas, sobre o reservatório de Canoas I, sob concessão da Duke Energy, atualmente CTG Brasil. Os resultados mostraram que, o algoritmo baseado na técnica RCEN modificada mostrou-se eficiente para a detecção de mudanças de forma automática.
\end{abstract}

\footnotetext{
${ }^{1}$ Universidade Federal Rural da Amazônia - UFRA. Instituto Ciberespacial - ICIBE, Brasil. E-mail: carlos.caldeira@ufra.edu.br

2Universidade Estadual Paulista - UNESP. Faculdade de Ciências e Tecnologia - FCT / Departamento de Cartografia, Brasil. E-mail: \{galo; nnimai; mlourdes; hasegawa; amorim; miltonhs\}@fct.unesp.br ${ }^{3}$ CTG Brasil. Gerência de Patrimônio / UHE Chavantes, Brasil. E-mail: marcelo.pinto@ctgbr.com.br
} 
PALAVRAS-CHAVE: Técnicas de Detecção Automática de Mudanças. Sensoriamento Remoto. Uso da Terra.

\begin{abstract}
Perform change detection of Earth's surface features is important to understand both the dynamics of the phenomena and for the prediction of impacts and to support decision-making. During the last decades were developed several change detection techniques from images, among them those based on remote sensing images. In general, the change detection involves the use of a set of multi-temporal data, which permits quantitative analysis of the phenomenon of interest. An application of great interest of these techniques is the automatic detection of changes in the vicinity of reservoirs, which can be used as auxiliary data in a monitoring system of the areas of interest. In such a system it is expected that the changes resulting from human activity are detected even if there are factors that cause differences between scenes, such as atmospheric conditions, scene lighting, sensor view point, soil moisture, among other factors. Considering this context, this paper presents the evaluation results of a change detection approach based on a modification applied to the RCEN (Radiometric Rotation Controlled by Non change axis) technique. The method was implemented and applied to a set of orthorectified images obtained by orbital system SPOT 6, taken at two different times on the Canoas I reservoir, under concession from Duke Energy (currently CTG Brasil). The results showed that the algorithm based on modified RCEN technique was efficient to detect automatically changes.
\end{abstract}

KEYWORDS: Automatic Detection Techniques changes. Remote sensing; Land Use.

\title{
Introdução
}

Nas últimas quatro décadas, imagens orbitais passaram a ser frequentemente utilizadas em pesquisas ligadas a aplicações ambientais, geológicas e oceanográficas, atuando como ferramenta auxiliar e por vezes principal na detecção de mudanças.

Em geral, a detecção de mudanças envolve a utilização de dados multitemporais, que são utilizados na detecção de alterações, seguida da análise quantitativa dos efeitos do fenômeno avaliado. De acordo com Lu et al. (2004), devido às vantagens decorrentes da aquisição repetitiva de dados, de sua visão sinóptica, e disponibilização em formato digital adequado para o processamento em computador, os dados de sensoriamento remoto, 
principalmente orbital, tornaram-se as principais fontes de dados em diferentes aplicações de detecção de alterações.

A premissa básica da utilização de dados de sensoriamento remoto na detecção de alterações é que as mudanças nos objetos de interesse resultam em variações nos valores de reflectância ou na textura local, que podem ser separadas de mudanças causadas por outros fatores, como diferenças nas condições atmosféricas, iluminação, ângulo de visada e umidade do solo (DEER, 1995). Considerando que a detecção de alterações é afetada por restrições espaciais, espectrais, temáticas e temporais, projetar um conjunto de algoritmos capazes de detectar de modo eficiente às alterações de interesse não é uma tarefa simples. Por causa dos impactos de fatores complexos, citado anteriormente, tais como diferenças nas condições atmosféricas, iluminação, ângulo de visada, entre outros, muitas vezes, diferentes autores chegaram a diferentes e por vezes controversas conclusões sobre quais técnicas de detecção de mudança são mais eficazes. Por isso, uma revisão das técnicas de detecção de mudança utilizadas em pesquisas e aplicações anteriores é útil para entender como essas técnicas podem ser melhores utilizadas para ajudar a resolver os problemas concretos.

Em um estudo realizado em Caldeira (2016), mostrou-se que existem muitos métodos diferentes em uso, desenvolvidos ao longo de várias décadas de sensoriamento remoto por satélite. No entanto, a maioria dos autores concordam que uma técnica de deteç̧ão de mudança universal ainda não existe (EHLERS et al., 2014) deixando os usuários com uma tarefa cada vez mais difícil de selecionar uma abordagem adequada na solução de seu problema. Por exemplo, Lu et al. (2004) apresentam 31 (trinta e uma) técnicas, que são classificadas em 7 (sete) categorias, o que mostra a diversidade de alternativas. Em geral, os processos de detecção de mudanças geralmente envolvem a atividade intensiva de um analista preparado para esse tipo de tarefa. Esse tipo de atividade poderia ser minimizado com a adoção de um sistema computacional projetado para realizar a maioria dos 
processamentos automaticamente, principalmente para áreas de grande dimensões.

Para comparar imagens multissensor tomadas em duas datas diferentes, Maldonado et al. (2007) apresentam uma técnica denominada RCEN (Radiometric Rotation Controlled by No change Axis) baseada em uma rotação controlada dos eixos ortogonais do espaço de atributos radiométricos das imagens (mesma banda espectral em diferentes datas), em relação ao eixo formado a partir de pontos de não-mudança. Essa técnica, denominada rotação radiométrica controlada por eixo de não-mudança - RCEN é bastante flexível e dispensa a correção dos efeitos atmosféricos ou de diferenças entre os sensores (ARASATO et al., 2012).

Essa flexibilidade é importante em algumas aplicações, quando se coloca a necessidade de automação no processo de detecção de alterações. Um exemplo de aplicação em que a automação do processo é relevante é o monitoramento de alterações de áreas marginais dos reservatórios de UHEs (Usinas Hidrelétricas), uma vez que as concessionárias de UHEs são responsáveis por garantir a manutenção das margens dos reservatórios sob sua concessão, tanto por imposição legal, quanto pela necessidade de minimizar processos erosivos responsáveis pela diminuição da vida útil dos reservatórios, como pode-se ver em (CALDEIRA et al., 2016). Nesse sentido, face à necessidade de fiscalizar as áreas sob sua concessão, surgiu a possibilidade de utilizar imagens multiespectrais e multitemporais de satélite para detectar alterações nas áreas marginais aos reservatórios, ou mais especificamente, nas Áreas de Proteção Permanente (APP), e utilizar essa informação para otimizar o processo de fiscalização nessas áreas.

Deste modo, o uso combinado de imagens de sensoriamento remoto de alta e média resoluções, mesmo considerando as limitações inerentes às imagens de média resolução, pode constituir uma abordagem de maior interesse para esse tipo de monitoramento. Nesse contexto, e com o objetivo de contribuir para a especificação de um conjunto de algoritmos adequados para uma abordagem automática de deteç̧ão de alterações foram analisados 
os resultados da aplicação de uma abordagem baseada na técnica RCEN. Esta abordagem foi considerada em função da facilidade da sua aplicação e dos resultados obtidos pelo método RCEN original, como pode-se ver em Maldonado et al. (2007) e Arasato et al. (2012), indicando que é possível incorpora-lo na especificação de um sistema computacional de detecção automática de mudanças. Sendo assim, o propósito central deste trabalho consiste em implementar e testar o método de deteç̧ão de mudanças RCEN modificado, a partir de uma série temporal de imagens orbitais, aplicando os testes em áreas no entorno do reservatório de Canoas I.

\section{Detecção Automática de Alterações}

Mudanças na cobertura terrestre são fenômenos inerentes ao mundo dinâmico e podem ocorrer em diferentes escalas e a diferentes taxas ao longo do tempo. A dinâmica dos tipos de mudança depende de fatores naturais ou artificiais e podem afetar seriamente o meio ambiente e os processos ambientais (ARASTOO e GHAZARYAN, 2013). Desse modo, uma resolução temporal adequada e uma abordagem precisa de detecção das mudanças da superfície física da Terra fornecem a base para uma melhor compreensão das relações e interações entre os fenômenos naturais e antrópicos e possibilitam melhor gerir e utilizar os recursos disponíveis.

Uma variedade de técnicas de deteç̧ão de mudanças tem sido desenvolvidas, e muitos autores documentaram, revisaram e compararam essas técnicas, como pode-se ver em Lu et al. (2004) e Tewkesbury et al. (2015). Devido à importância cada vez maior de monitorar as mudanças na superfície da Terra, a pesquisa por técnicas de detecção de mudanças é um tópico ativo e novas técnicas são constantemente desenvolvidas.

Todas as técnicas de detecção de alterações têm vantagens e desvantagens, de modo que indicar um método como o melhor ou a técnica como a mais aplicável para todas as situações é impossível. A técnica mais adequada para cada situação é definida, principalmente pela natureza e 
características do fenômeno que se pretende monitorar, mas também em função das imagens disponíveis para tal tarefa. Além disso, segundo Arastoo e Ghazaryan (2013), fatores como: a abrangência espectral de dados, acessibilidade e qualidade dos dados, condições ambientais, conhecimento e habilidade do analista, tempo e o custo, também são determinantes na seleção da técnica mais apropriada.

Via de regra, conforme destacado por Arastoo e Ghazaryan (2013), um estudo adequado de deteç̧ão de alterações, em relação à técnica aplicada, deve fornecer informações como: área e a taxa de alteração, distribuição espacial das alterações, tendência de mudanças em diferentes tipos de cobertura da terra, bem como a possibilidade de avaliar a exatidão dos resultados obtidos. Essa mesma colocação foi feita anteriormente por Lu et al. (2004), ao relatarem que uma pesquisa fundamentada sobre deteç̧ão de mudanças deve fornecer as seguintes informações: (a) variação de área e a taxa de alteração; (b) a distribuição espacial dos tipos alterados; (c) as trajetórias das mudanças em relação aos tipos de cobertura do solo; e (d) a avaliação da acurácia na deteç̧ão da mudança. Ainda segundo estes autores, na implementação de um projeto de deteç̧ão de mudanças, três etapas principais estão envolvidas: (a) pré-processamento das imagens, incluindo retificação geométrica e registro, correção radiométrica e atmosférica, quando necessária, além de uma ortorretificação das imagens; (2) seleção de técnicas adequadas para implementar a deteç̧ão de alterações; e (3) avaliação precisa das mudanças. O desenvolvimento que consistente dessas etapas, segundo Lu et al (2004), depende de muitos fatores, incluindo:

a) Registro geométrico preciso entre imagens multitemporais;

b) Calibração e/ou normalização radiométrica entre imagens multitemporais;

c) A disponibilidade de referência terrestre para análise de qualidade;

d) A complexidade da paisagem e do ambiente da área de estudo;

e) Métodos de detecção de mudança e algoritmos utilizados,

f) Os sistemas de classificação e de detecção de mudanças; 
g) As habilidades e experiência do analista;

h) Conhecimento e familiaridade com a área de estudo; e

i) Restrições de tempo e custo.

1.1 Processamentos prévios à aplicação de técnicas de deteç̧ão de mudanças em Sensoriamento Remoto

Lu et al. (2005) destacam que para implementar uma técnica de deteç̧ão de mudanças a partir de dados de sensoriamento remoto, e para que esta detecção seja bem sucedida, é necessário levar em conta vários aspectos. Esses aspectos referem-se a fatores como: as características do sistema sensor, características ambientais e os métodos de processamento e análise de imagens. Para se obter bons resultados em um projeto de detecção de mudanças, as resoluções: temporal, espacial, espectral e radiométrica dos dados de sensoriamento remoto têm um impacto significativo. As condições atmosféricas, condições de umidade do solo e características fenológicas da vegetação, como destacado por Jensen et al. (1997), são os fatores ambientais mais importantes e que devem ser levados em conta. Dos vários requisitos relacionados ao pré-processamento para detecção de mudanças, o registro multitemporal e as correções radiométrica e atmosférica são os mais importantes. A importância de registro geométrico preciso das imagens multitemporais é simples de se entender, pois resultados espúrios de detecção de alterações serão produzidos se houver erro de registro, causando assim "detecções fantasmas" e que podem corresponder a falsos positivos na avaliação da qualidade.

Complementando os raciocínios anteriores Lu et al.(2004) colocam que, em algumas situações específicas de detecção de alterações, devem ser contempladas outras condições como: as imagens multitemporais devem contemplar estágios fenológicos similares, quando se trata da cobertura vegetal e prever a necessidade de ajustes entre imagens multitemporais obtidas por diferentes sensores, quando não for possível dispor de dados de mesma resolução espacial e espectral. 
Segundo Tewkesbury et al. (2015), devido ao impacto de fatores complexos, muitas vezes, diferentes autores chegam a conclusões diferentes, e por vezes controversas, sobre quais técnicas de detecção de alterações seriam mais eficientes em situações similares. Na prática, a escolha de um algoritmo apropriado para deteç̧ão de uma mudança específica não é trivial e essa especificação torna-se ainda mais complexa quando se trata da deteç̧ão simultânea e automática de mudanças que ocorrem em diversas escalas temporais e espaciais.

\subsection{Técnica RCEN (Radiometric Rotation Controlled by No change axis)}

A técnica RCEN é uma técnica de deteç̧ão de mudanças que foi proposta por Maldonado et al. (2007). Os resultados da aplicação desta técnica chamaram atenção para a detecção de mudanças de forma automática, pois a mesma é bastante flexível e dispensa a correção dos efeitos atmosféricos ou de diferenças entre os sensores (ARASATO et al., 2012).

Esta técnica baseia-se em uma regressão linear dos valores de radiometria dos locais de amostragem de não mudança, definidos a partir de um levantamento de campo. Para esta regressão são utilizados os valores de ND (Número Digital) de duas imagens, sendo a primeira correspondente à primeira data do período de detecção e a segunda à segunda data. A equação de regressão dos pontos de não mudança é obtida a partir da Equação 1, onde "m" é o coeficiente angular da reta de regressão, $\operatorname{com} m=\tan (\theta)$, sendo $\theta$ a inclinação do eixo de não mudança, como pode-se ver em Maldonado et al. (2007).

$$
I_{D_{2}}=m I_{D_{1}}+O
$$

onde O: origem da interceptação; $I_{D 1}$ e $I_{D 2}$ valores de ND das imagens das datas $\mathrm{D} 1$ e D2, respectivamente. 
Este ângulo $(\theta)$ é o parâmetro principal da rotação, sendo utilizado na equação da transformação da técnica RCEN dada pela Equação 2, apresentada por Maldonado et al. (2007). Assumindo que as imagens de uma mesma região nas datas D1 e D2 sejam representadas respectivamente por $I_{D 1}$ e $I_{D 2}$, a imagem residual ( $I_{R e s}$ ) e a imagem de deteç̧ão de mudanças ( $\mathrm{I}_{\text {detecção), }}$, como definida pelos autores, podem ser obtidas por:

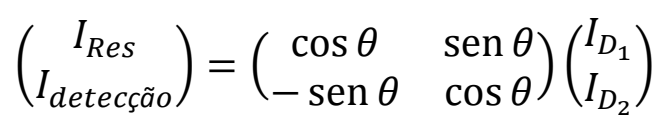

Esta transformação corresponde a uma rotação dos eixos ortogonais do espaço de valores radiométricos das imagens (de uma mesma banda espectral em datas diferentes). Como resultado tem-se duas imagens, sendo a imagem $\left(\mathrm{I}_{\text {Res }}\right)$ denominada pelos autores imagem residual, não utilizada no processo

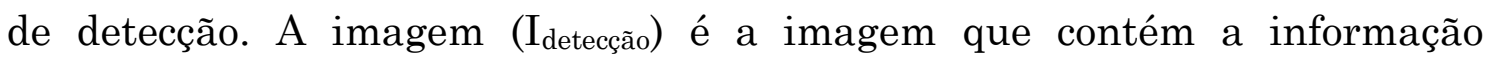
relacionada aos pontos onde ocorreram mudanças entre as datas D1 e D2 analisadas.

A imagem deteç̧ão é formada utilizando valores no domínio dos números reais, apresentada na Equação 3. Nesta imagem os tons claros (valores altos) são os pixels que representam alvos que surgiram de um ano para outro, ou seja, alvos que não existiam na época $I_{D 1}$ e passaram a existir na época $I_{D 2}$. Os pixels com tons mais escuros (valores baixos) representam o comportamento ao contrário, isto é, são alvos que deixaram de existir de uma época para outra. Assim, aplicando a rotação dada pela Equação 2 a imagem de detecção $\left(I_{\text {deteçãoo }}\right)$ é dada por.

$$
I_{\text {deteç̧̃ } \tilde{o}}=\cos \theta I_{D_{2}}-\sin \theta I_{D_{1}}
$$




\section{Materiais e Métodos}

Para o desenvolvimento deste trabalho, inicialmente realizou-se um levantamento bibliográfico dos trabalhos relacionados ao tema, detecção de mudanças, o que permitiu a proposição do método apresentado na Seção 2.3.

$\mathrm{Na}$ sequência será descrita a área de estudo, os materiais utilizados, bem como o método proposto para atender aos objetivos apresentados neste trabalho.

\section{1 Área de Estudo}

As UHEs Canoas I e Canoas II, junto com seus reservatórios, compõem o Complexo Canoas, que se localizam no médio curso do rio Paranapanema, na divisa dos estados de São Paulo e Paraná. Elas estão entre a UHE Salto Grande (a montante) e a UHE Capivara (a jusante). A Figura 1 apresenta a localização do reservatório do empreendimento Canoas I, que pertence a dois municípios paulistas, Cândido Mota e Palmital e dois paranaenses, Itambaracá e Andirá.

Esse complexo hidrelétrico é do tipo "a fio d'água”, não possuindo capacidade de retenção, ou seja, as águas são totalmente liberadas pelas turbinas e por estruturas de vertimento. Os reservatórios das UHEs Canoas I e Canoas II possuem um perímetro total de $223 \mathrm{~km}$, nas cotas $351 \mathrm{~m}$ e 366 $\mathrm{m}$, respectivamente. 
Figura 1 - Localização do reservatório Canoas I.

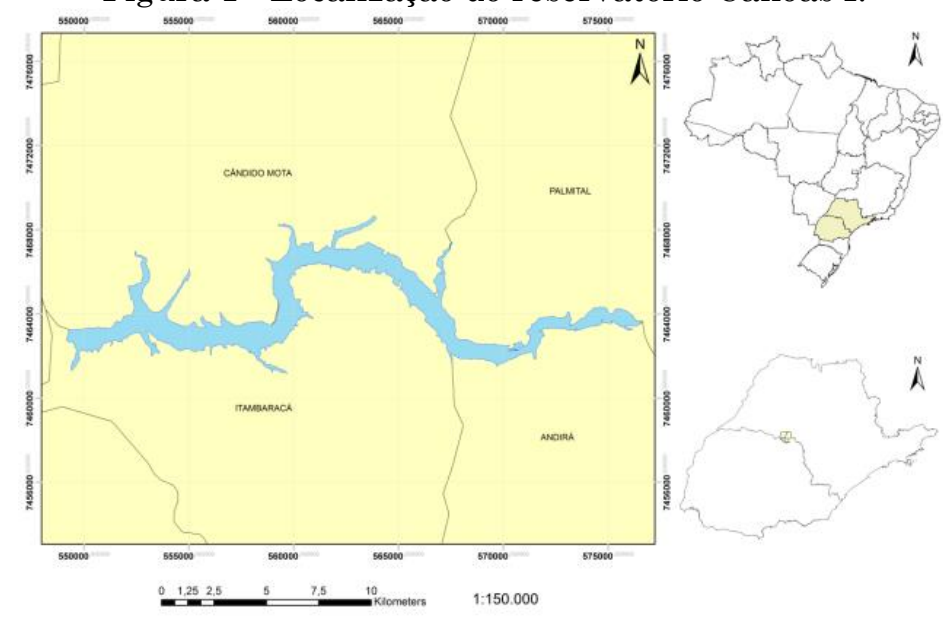

Fonte: Elaborada pelo autor.

2.2 Área de Estudo

Os dados utilizados neste projeto, visando a detecção de mudanças de forma automática foram disponibilizados pela empresa Duke Energy, atualmente CTG Brasil. Estes dados são referentes às Usinas Hidrelétricas instaladas ao longo do rio Paranapanema, que são: Canoas I e Canoas II. Dentre estes reservatórios, foram selecionados os dados de Canoas I para a realização dos testes, já que o mesmo apresentava maior variabilidade e representatividade das possíveis intervenções.

Estes dados são basicamente imagens orbitais ortorretificadas do sensor SPOT 6. O Quadro 1 exibe as especificações técnicas das imagens do sensor SPOT 6.

Quadro 1: Especificações das imagens do sensor SPOT 6.

\begin{tabular}{|c|c|c|}
\hline \multirow{5}{*}{$\begin{array}{l}\text { Bandas espectrais/ Intervalo do comprimento de } \\
\text { onda }\end{array}$} & Pancromática & $0,450-0,745 \mu \mathrm{m}$ \\
\hline & Azul & $0,450-0,520 \mu \mathrm{m}$ \\
\hline & Verde & $0,520-0,590 \mu \mathrm{m}$ \\
\hline & Vermelho & $0,625-0,695 \mu \mathrm{m}$ \\
\hline & $\begin{array}{l}\text { Infravermelho } \\
\text { próximo }\end{array}$ & $0,760-0,890 \mu \mathrm{m}$ \\
\hline Resolução Radiométrica & \multicolumn{2}{|c|}{12 bits } \\
\hline \multirow{2}{*}{ Resolução Espacial } & Pancromática & $2 \mathrm{~m}$ \\
\hline & Multiespectral & $6 \mathrm{~m}$ \\
\hline
\end{tabular}

Fonte: Elaborada pelo autor. 
As imagens utilizadas foram adquiridas em 5/11/2012 e 29/04/2013, como mostrado nas Figuras 2.a e 2.b.

Figura 2 - Recorte do reservatório de Canoas I, composições coloridas (R, G, B), nas datas $5 / 11 / 2012$ (a) e 29/04/2013 (b).
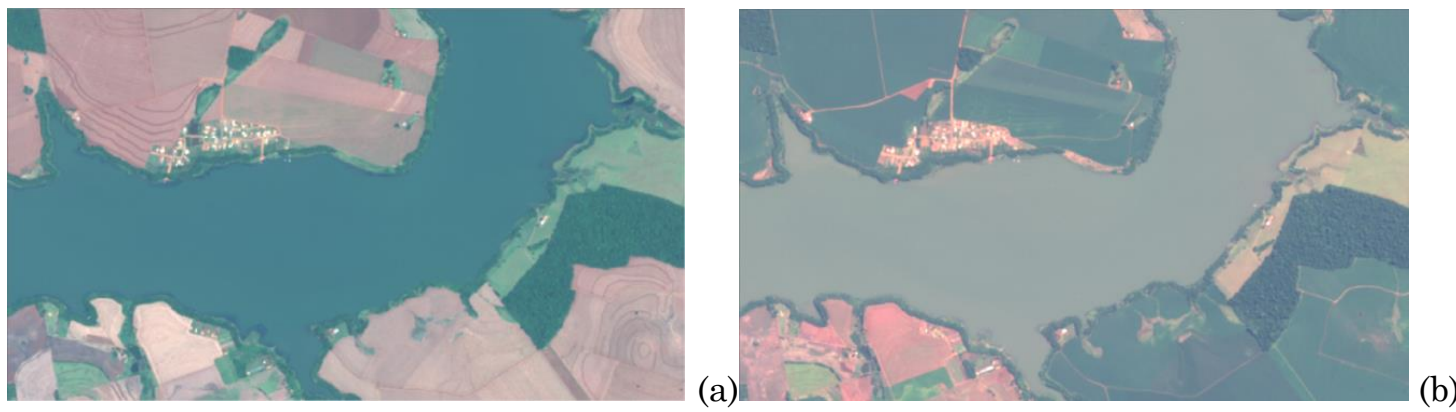

Fonte: Elaborada pelo autor.

Para cada uma das datas estão disponíveis imagens em quatro (4) bandas multiespectrais, como mostra a Figura 3, sendo as Bandas 1, 2, 3 e 4, associadas às bandas do Vermelho, Verde, Azul e Infravermelho Próximo, respectivamente.

Figura 3 - Recorte das imagens do sensor SPOT 6 do reservatório de Canoas I, representando as 4 bandas multiespectrais em 05/11/2012.

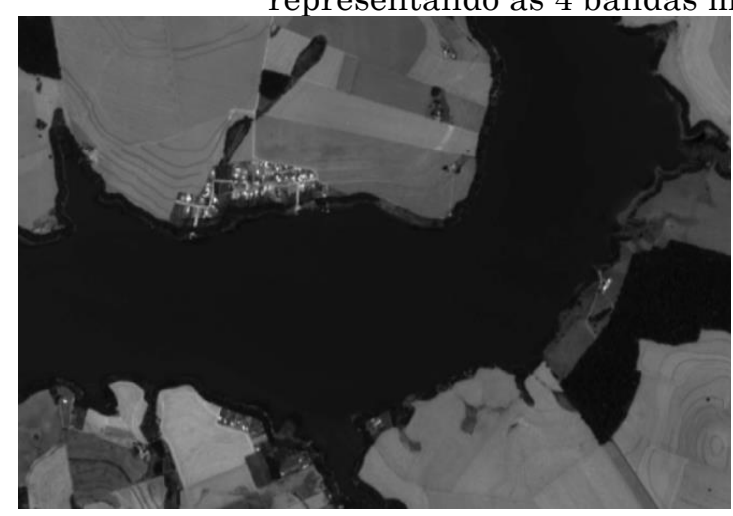

a) Banda do Vermelho

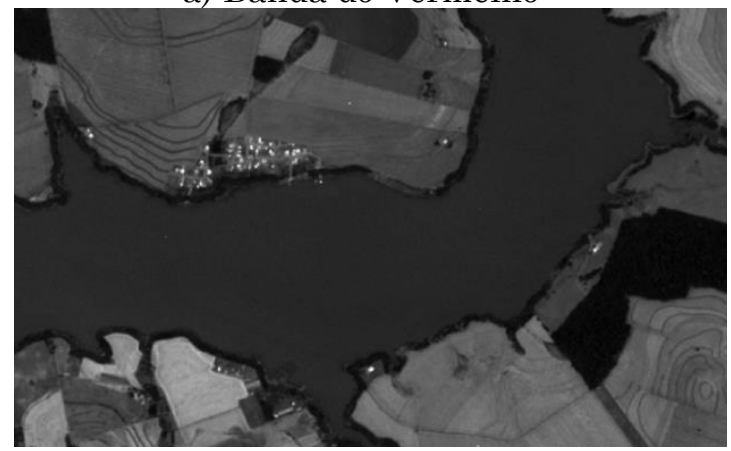

c) Banda do Azul

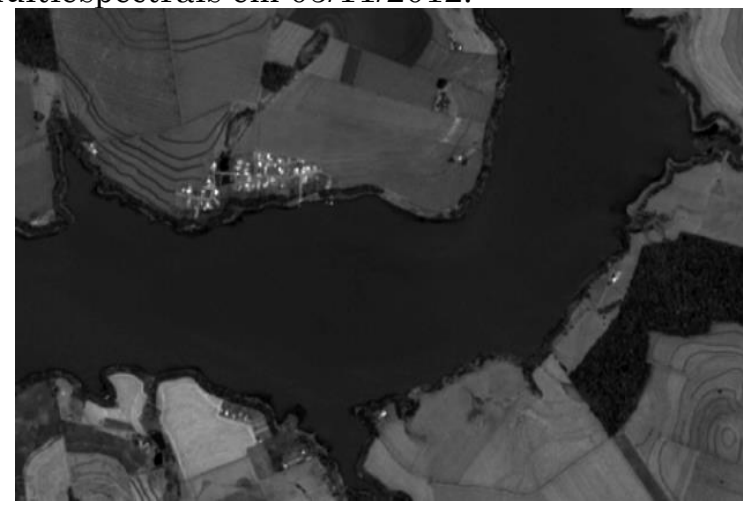

b) Banda do Verde

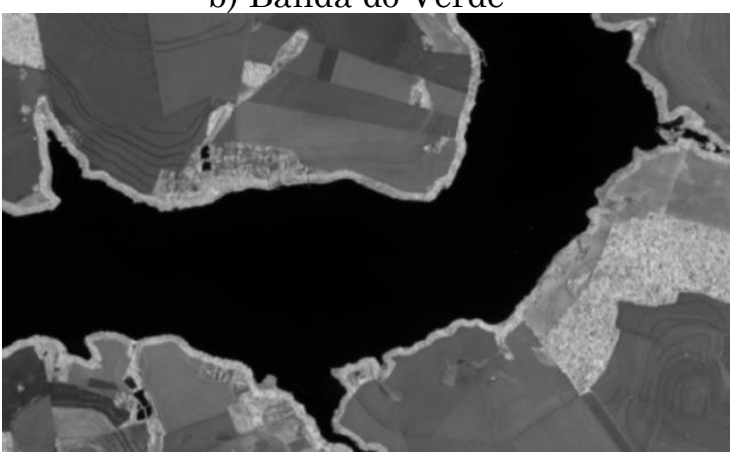

d) Banda do Infravermelho Próximo Fonte: Elaborada pelo autor. 
Além das imagens orbitais, a empresa Duke Energy/CTG Brasil, também disponibilizou um mapa do uso do solo (elaborado em 15/08/2014), em arquivo no formato shapefile, como mostra a Figura 4. Este mapa é útil para a análise da qualidade, servindo também como uma referência para a separação das diferentes classes de cobertura do solo. Esta separação pode ser feita a partir de máscaras definidas a partir de arquivos shapefile, que contém algumas classes que não são de interesse para o processamento.

Figura 4 - Mapa do uso do Solo de Canoas I.

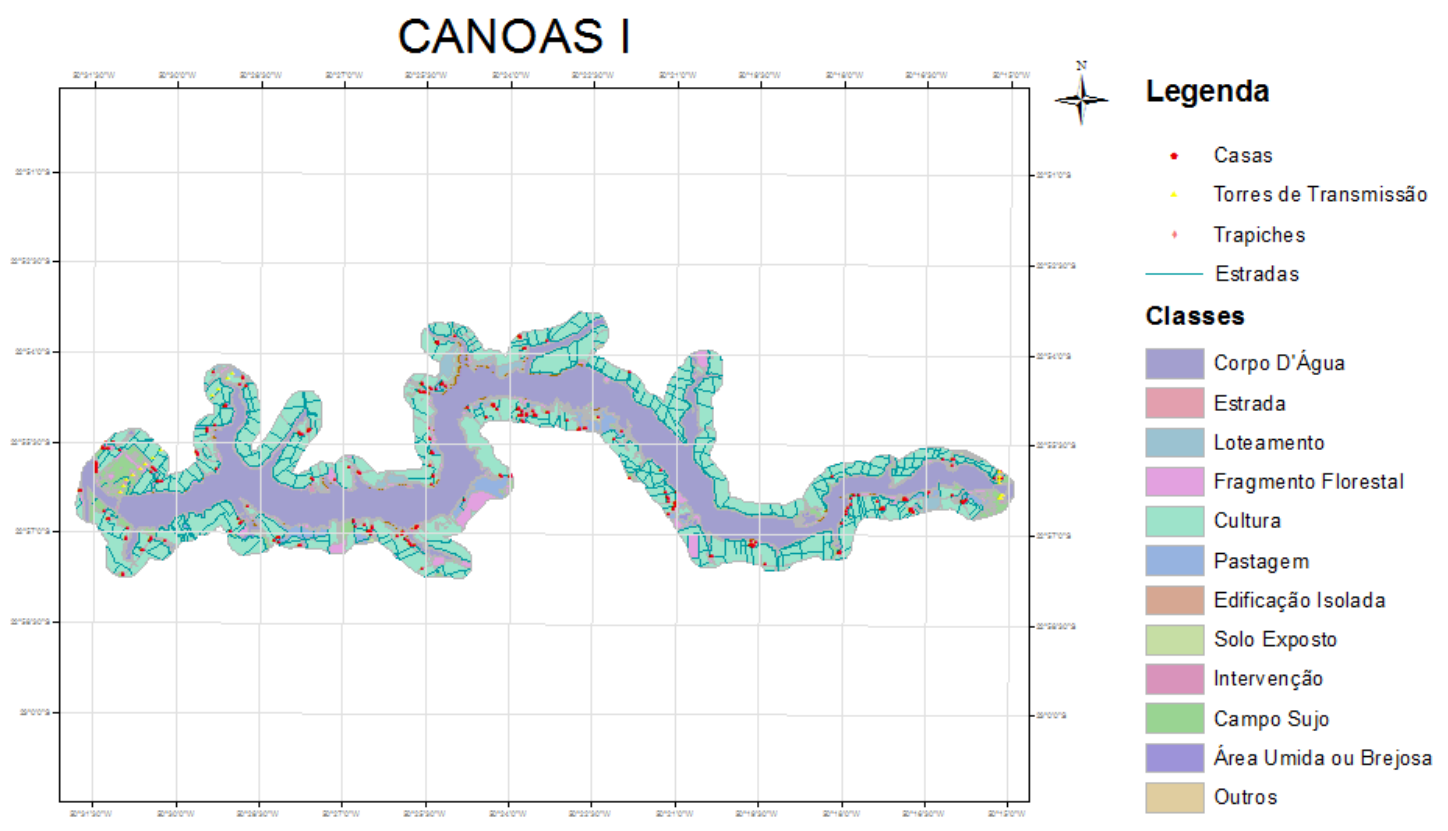

Fonte: Elaborada pelo autor.

Para selecionar algumas áreas testes, onde há uma maior concentração de intervenções, utilizou-se da interpretação visual, realizada a partir das imagens ortorretificadas do sensor WordView II, com resolução espacial de 2 $\mathrm{m}$ nas quatro bandas multiespectral e $0,50 \mathrm{~m}$ na banda pancromática, adquiridas em 11/09/2013. As imagens de alta resolução espacial foram utilizadas apenas como auxílio para a visualização dos dados e interpretação dos mesmos.

Para a redução da área de análise, concentrando o processamento apenas na área de interesse da empresa hidroelétrica, utilizou-se um arquivo 
em formato shapefile, como mostrado na Figura 5, contendo os limites da área de estudo. Este limite trata-se da Maximorum, que é estabelecida quando o nível de água atinge o ponto mais elevado para o qual a barragem foi projetada. É geralmente fixado como o nível correspondente à elevação máxima, quando da ocorrência de cheia de projeto. Para este estudo de caso o buffer será de 50 metros, contada da margem do rio.

Figura 5 - Imagem obtida pelo sensor SPOT 6 (data 05/11/2012) do reservatório Canoas I mostrando o limite da área de estudo.

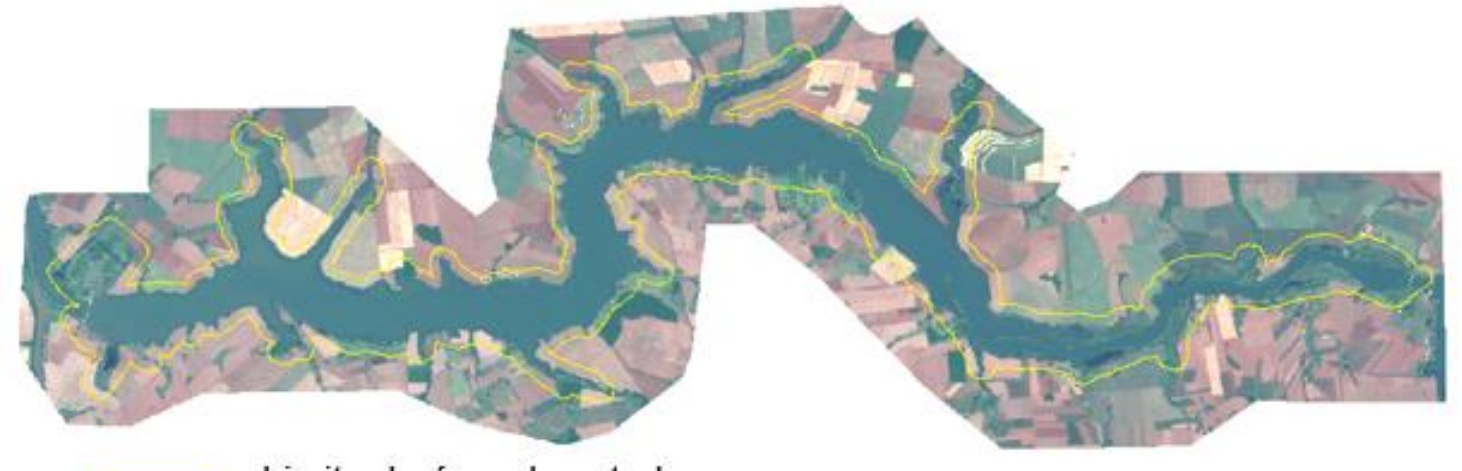

Limite da área de estudo

Fonte: Elaborada pelo autor.

Durante o desenvolvimento deste trabalho foram utilizados diferentes softwares: MATLAB (MATrix LABoratory) - na etapa de testes dos algoritmos utilizados; ENVI 5.0 - usado para realizar as etapas de préprocessamento, incluindo o refinamento do registro das imagens; ArcGis 10.0 - utilizado na etapa de elaboração da verdade terrestre; Python 2.7 - para a codificação dos algoritmos de detecção de mudanças; PostgreSql 9.4 - usado para o gerenciamento do banco de dados e PostGis 2.2.4 -usado para a manipulação dos dados georreferenciados, respectivamente.

\subsection{Método RCEN modificado}

Esta subseção apresenta a ideia geral do método proposto neste artigo. Este método baseia-se na técnica de deteção RCEN, que faz a transformação 
de rotação em torno de um eixo, que representa a relação entre a resposta espectral dos pixels que não sofreram alteração, em duas datas, como descrito na Seção 1.2. Como mencionado na fundamentação, o método original foi proposto por Maldonado et al. (2007). Na aplicação do método original as seguintes premissas são válidas:

- A maioria dos pixels de duas imagens numa banda espectral de uma mesma região não se altera num curto período de tempo, principalmente em regiões monitoradas;

- O eixo de não mudança forma um ângulo $\theta$ que indica a posição relativa de não-mudança;

- O eixo de não-mudança é obtido por regressão linear dos valores radiométricos amostrados em locais de não mudança;

- Bandas espectrais adequadas devem ser escolhidas de acordo com o alvo de interesse;

- A compatibilidade radiométrica entre as bandas envolvidas é garantida;

- O método é robusto mesmo para comparar dados de diferentes sensores.

Como destacado anteriormente, um dos pressupostos considerado por Maldonado et al. (2007) ao aplicar o método, foi de que o eixo de não mudança é obtido a partir da informação em regiões onde não ocorreram mudança. Assim, se assumirmos que o nível de mudanças não é o que predomina ao comparar imagens de duas épocas, considera-se que o eixo de não mudança pode ser estimado a partir da imagem como um todo, ou seja, sem que seja feita uma pré-seleção de locais de não mudança.

Desta forma, passa-se a descrever o método de detecção denominado RCEN modificado. O ângulo de rotação $\theta$ (determinado pelo eixo de não mudança) é obtido pela aplicação de uma regressão linear nos valores de ND de bandas espectrais correspondentes, sendo que pequenas variações na largura de banda ou na sua sensibilidade podem ser assimiladas pela 
transformação aplicada. Deste modo, a partir de imagens de duas épocas, de uma determinada banda, tem-se a Figura 6, que mostra alguns elementos essenciais para o desenvolvimento da equação que será desenvolvida.

Figura 6 - Representação gráfica da linha de não mudança e do valor de IINT (imagem intermediária).

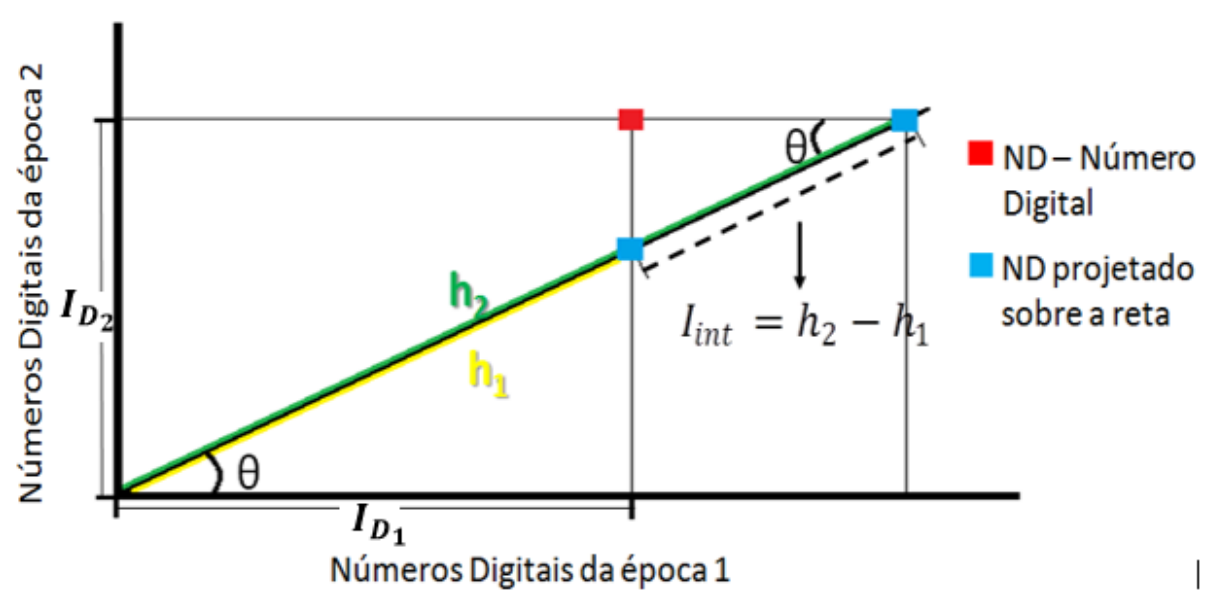

Fonte: Elaborada pelo autor.

Considerando um determinado pixel com valores de $\mathrm{I}_{\mathrm{D} 1}$ e $\mathrm{I}_{\mathrm{D} 2}$, nas duas épocas, respectivamente, caso ele esteja sobre a reta de coeficiente angular $\tan (\theta)$ significa que este pixel não apresentou mudanças. Caso este pixel esteja disposto como na Figura 6 (ponto em vermelho), a distância entre as projeções (em azul na figura) será um indicador de que este pixel sofreu mudanças entre as épocas analisadas. Assim, o valor de InNT (Equação 4) poderá ser estimado pela diferença de distância $\mathrm{h}_{2}-\mathrm{h}_{1}$. Deste modo, aplicando as funções trigonométricas adequadas a cada um dos triângulos pode-se determinar os valores de $\mathrm{h}_{1} \mathrm{e} \mathrm{h}_{2}$ em função dos valores de $\theta$, ID1, ID2, bem como de b (coeficiente linear da reta de não mudança), ou seja:

$$
I_{I N T}=(\cos \theta)^{-1} * I_{D 1}-(\operatorname{sen} \theta)^{-1} *\left(I_{D 2}-b\right)
$$

A inserção do coeficiente linear b na Equação 4 é justificada pelo fato de que, segundo a Figura 6, a reta está passando pela origem, ou seja, representando um caso ideal. Caso a reta não esteja passando pela origem é 
necessário que a mesma seja transladada para a origem, por meio do coeficiente linear. O resultado da operação acima produz a imagem intermediária ( $\mathrm{I}_{\mathrm{INT}}$ ), que tem relação com as mudanças ocorridas, ou seja, quanto maior for o valor resultante, maior será a mudança ocorrida. Pode-se notar na Figura 6 que os pontos a serem analisados (em vermelho no exemplo mostrado) podem estar acima ou abaixo da reta de coeficiente angular tan $(\theta)$, o que resulta em valores positivos e negativos para IINT.

$\mathrm{Na}$ sequência são ilustradas duas situações que permitem entender melhor o que foi apresentado em relação ao eixo de não mudança. Caso os valores de NDs das duas datas estejam sobre a reta de não mudança, a diferença resultante será nula, tendo-se uma situação ideal como mostrado na Figura 7.

Fig. 7 - Situação simulada onde não há mudança entre as datas, em (a) Imagem na época 1, em (b) Imagem na época 2 e em (c) Eixo de não mudança, situação ideal.

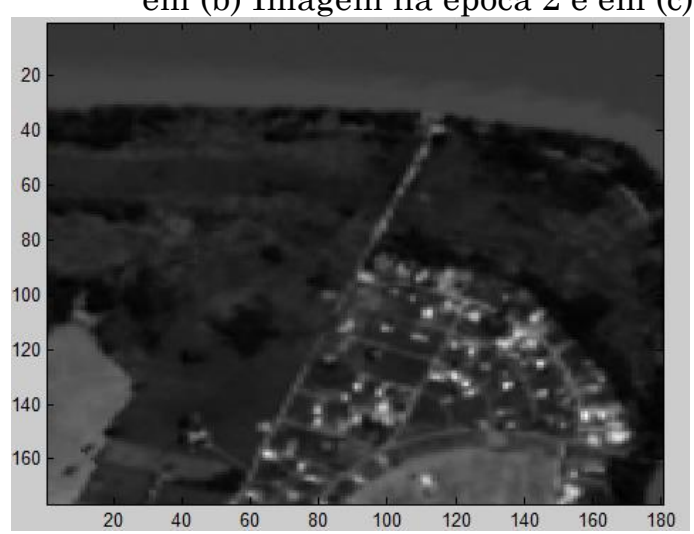

(a)

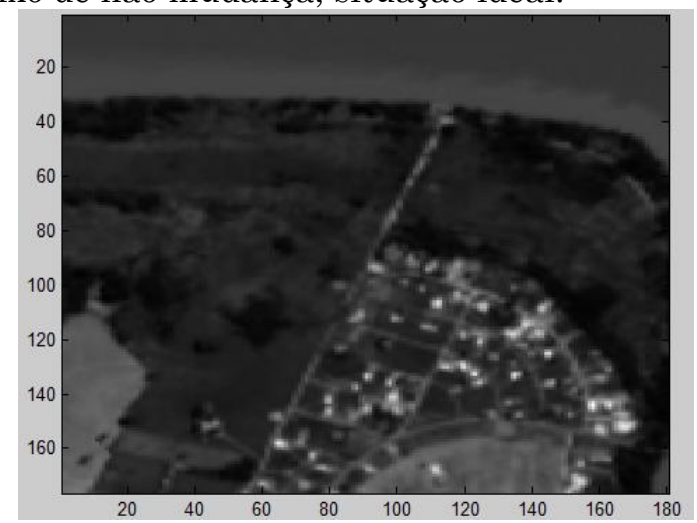

(b)

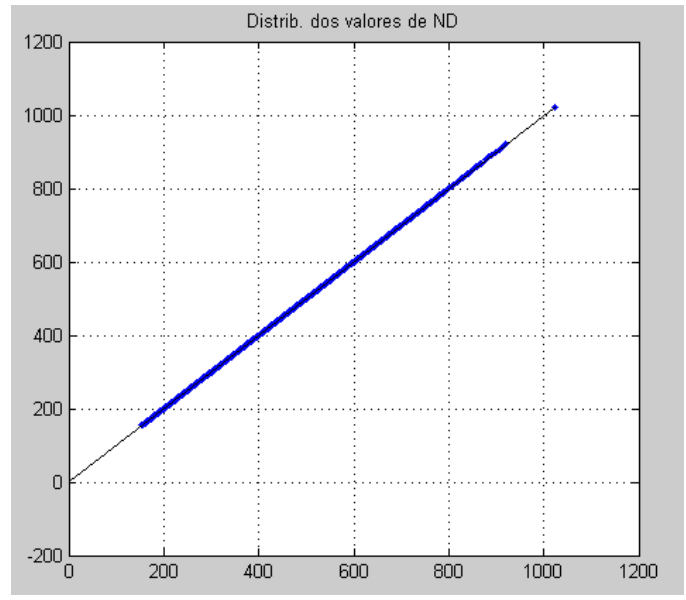

(c)

Fonte: Elaborada pelo autor. 
Na Figura 7 pode-se perceber que considerando uma situação hipotética onde não há mudanças entre as épocas, os NDs ficam sobre a reta, sem que haja uma dispersão. Neste exemplo utilizou-se o mesmo segmento de imagem nas duas épocas, apenas para efeito de simular uma situação ideal de não mudança.

Quando se coloca um segmento de imagem diferente da época 1 (ver Figura 8), pode-se perceber a dispersão dos dados.

Figura 8 - Situação simulada onde há mudança entre as datas, o que ocorre com dados reais. Em (a) Imagem na época 1, em (b) Imagem na época 2 e em (c) Eixo de não mudança.

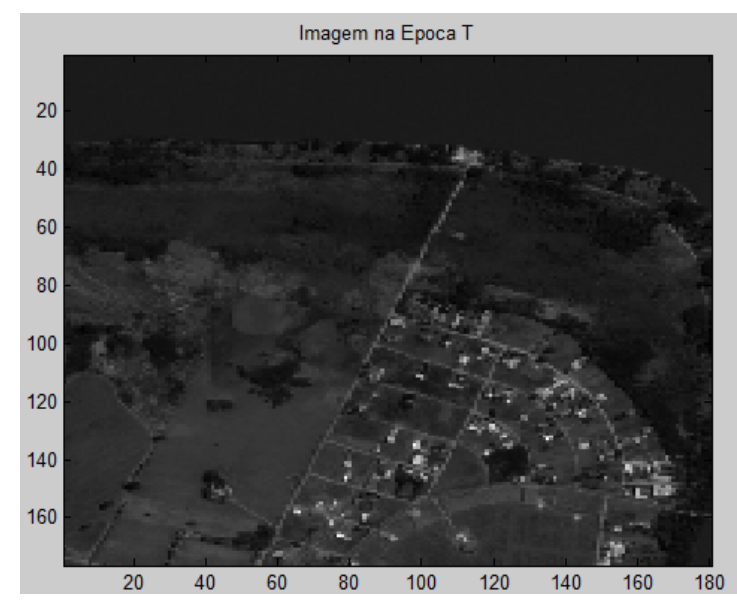

(a)

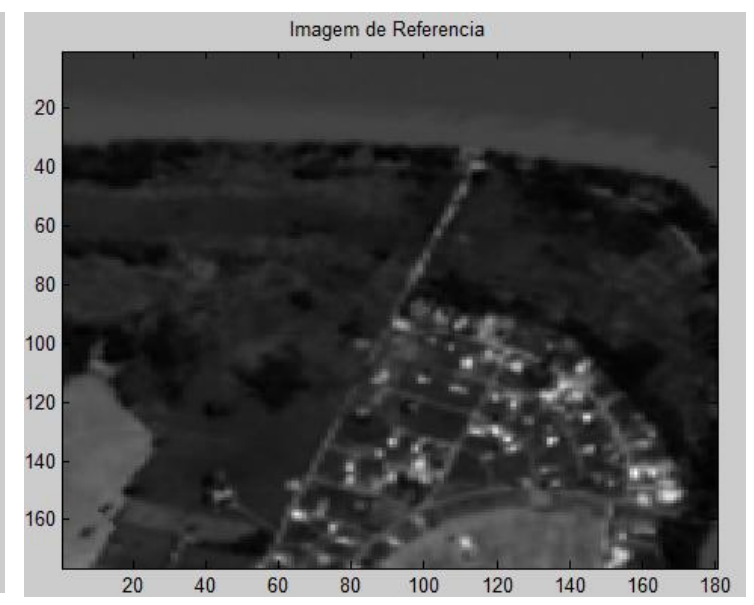

(b)

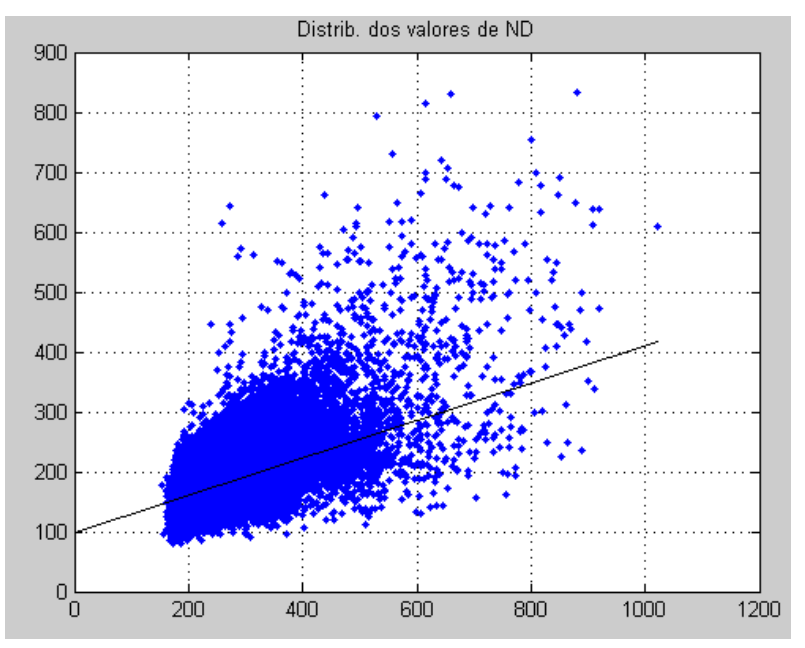

(c)

Fonte: Elaborada pelo autor. 
Com base nos valores intermediários calculados para cada banda espectral utilizada (nas duas datas), pela Equação 4, pode ser calculado o valor que deve indicar possíveis alterações. Na Equação 5 tem-se a imagem com o índice de alteração $\mathrm{I}_{\text {deteção }}$ calculado a partir de quatro bandas multiespectrais:

$$
I_{\text {detecção }}=I_{I N T, B 1}+I_{I N T, B 2}+I_{I N T, B 3}+I_{I N T, B 4}
$$

sendo $\mathrm{I}_{\mathrm{INT}}, \mathrm{B}_{\mathrm{i}}$, com i =1, 2, 3 e 4, os valores intermediários para quatro bandas. No presente caso estas bandas podem ser as 4 bandas multiespectrais do sensor SPOT 6.

O resultado da Equação 4, para uma determinada banda, será um número real. Por consequência o mesmo ocorrerá para o resultado da Equação 5. O resultado destas equações pode ser tanto positivo quanto negativos, indicando o aparecimento de "novas" feições bem como o "desaparecimento" de alguns objetos. A fim de realçar as mudanças mais significativas pode-se adotar um limiar (percentual) que permite realçar as mudanças de interesse. $\mathrm{Na}$ Seção 4 é feita a análise do comportamento dos indicadores de qualidade como função da mudança desse limiar.

\subsection{Estudos preliminares e desenvolvimento do método proposto}

A proposta metodológica deste trabalho consiste em estudar o método de deteç̧ão de mudanças RCEN modificado, no entorno de reservatórios, a partir de uma série temporal de imagens orbitais.

Como experimentos preliminares foram testados os métodos de deteç̧ão de mudanças RCEN modificado bem como o método baseado na diferença de NDVI, de modo a compará-los e avaliar qual dos métodos apresenta uma maior eficiência na deteç̧ão de mudanças, de modo automático. Os resultados preliminares foram apresentados em Imai et al. (2015), onde foi possível verificar que o algoritmo baseado no método RCEN 
modificado tem potencial para produzir informações adequadas para a análise automática de detecção de alterações, principalmente em comparação com o método de diferença de NDVI, onde o mesmo apresentou-se como sendo sensível a diferença sazonal entre as imagens. No método RCEN modificado a imagem de detecção final apresenta a contribuição das mudanças obtidas ao comparar uma mesma banda espectral, em diferentes datas, bem como outros conjuntos de bandas espectrais, dependendo do sensor utilizado. Esse resultado mostrou que o algoritmo tem comportamento robusto para o caso de imagens de períodos sazonais distintos e indica que as imagens intermediárias podem ser estudadas separadamente (usando distintas bandas), onde se notou que a banda 3 do sensor SPOT 6 é bem sensível a áreas que foram removidas, como, por exemplo, áreas com casas ou construções que estavam em situações ilegais e foram removidas de um ano para outro. Percebeu-se que a banda 1 do sensor SPOT 6 é sensível às construções que foram feitas entre as datas analisadas.

Estudos relacionados a outros métodos de detecção de mudanças, como, por exemplo, o método de subtração de imagens, pode ser visto em (CALDEIRA, 2016). Analisando os resultados concluiu-se que para a deteç̧ão automática de alterações, estes métodos não seriam viáveis, pois a ideia é que o usuário tenha o mínimo de interferência e dentre os métodos estudados o método RCEN modificado apresentou resultados promissores.

O desenvolvimento do método está dividido em duas partes, onde a primeira parte é de responsabilidade do usuário/operador. Nesta etapa as seguintes atividades devem ser realizadas: confirmar se todas as imagens estão ortorretificadas, se as imagens estão na mesma projeção e no mesmo referencial, se as imagens possuem o mesmo GSD (Ground Sample Distance) e se elas estão corretamente registradas.

Caso algumas destas características não sejam atendidas deve-se refazer o pré-processamento, de modo que ao final as imagens estejam ortorretificadas, possuam o mesmo GSD, estejam na mesma projeção e referencial e estejam corretamente registradas. 
Na próxima etapa (Parte 2) deve ser realizada a aplicação de máscaras, visando eliminar áreas que não são de interesse dos usuários, e que se mantidas no processamento geram um aumento nas detecções de mudanças que não são de interesse, prejudicando a análise. Exemplo: áreas de cultura no entorno do reservatório ficaria fora da área de interesse, pois são áreas regularizadas pelas UHEs. Sendo assim, caso haja modificações nestas áreas não serão de interesse do usuário. Após realizar as operações descritas anteriormente, deve-se aplicar a técnica de detecção de mudanças apresentada na Seção 2.3, sendo esta parte automatizada, não necessitando da interferência do usuário. Logo em seguida, realiza-se a validação do algoritmo, analisando os parâmetros de qualidade (Completeza, Nível de Acerto e Qualidade), descritos em Caldeira (2016), com base em Wiedemann et al. (1998).

\section{Resultados e Análises}

Uma vez definido o método a ser testado foram realizados alguns experimentos, visando avaliar diferentes aspectos, como, por exemplo: analisar o efeito da correção atmosférica na detecção de mudanças; analisar o efeito da exclusão de áreas que não são de interesse na minimização de falsos positivos; analisar a influência das bandas multiespectrais na detecção de mudanças e analisar o efeito da combinação das bandas. Com estes experimentos, pode-se chegar a uma imagem deteç̧ão ( $\left.I_{\text {detecção }}\right)$ final, onde as deteç̧ões aparecem em destaque em tons de cinza, sendo analisado os pixels mais escuros e mais claros das imagens como detecções de maior impacto (Figura 9). 
Figura 09 - Imagem $I_{\text {deteção. }}$

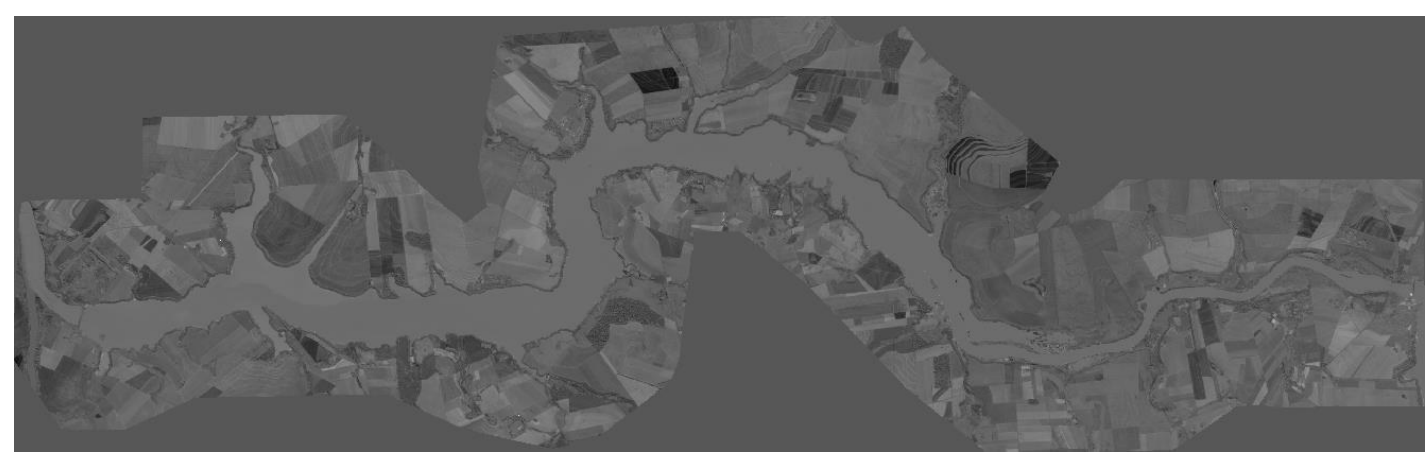

Fonte: Elaborada pelo autor.

Estes experimentos, bem como outros, como pode-se ver em Caldeira (2016), foram realizados e, após análise dos resultados obtidos para as diferentes classes, foi possível obter o Quadro 2, que traz um resumo das sugestões em termos de banda, ou combinação delas, juntamente com o melhor limiar (ou intervalo), que permitiram obter os melhores índices de qualidade. Deste modo, estes valores podem ser utilizados na detecção de mudanças de forma automática, para cada uma das classes de intervenções consideradas.

Quadro 2. Resumo das escolhas das melhores bandas, ou combinações delas, juntamente com o limiar escolhido.

\begin{tabular}{|c|c|c|}
\hline Classe & Banda ou Combinação de Banda & Limiar (\%) \\
\hline Construção & R & 40 \\
\hline Corpo D'Água & NIR & 80 \\
\hline Sombras & RB ou R & 15 a 60 \\
\hline Solo & RGB & 60 \\
\hline Vegetação & R & 50 \\
\hline
\end{tabular}

Fonte: Elaborada pelo autor.

Após análise dos resultados do Quadro 2, percebe-se que de um modo geral o uso da banda $R$, do sensor SPOT 6, resultou em um bom desempenho na maioria das classes. Porém, como não houve unanimidade em relação a 
uma banda, ou combinações de bandas para todas as classes, sugere-se que a detecção de mudanças de forma automática seja realizada por classes de interesse. Ou seja, antes de realizar a detecção de mudanças o usuário deverá escolher qual classe ele pretende detectar e assim o algoritmo irá utilizar a informação do Quadro 2, para realizar tais deteç̧ões.

Por fim, depois de todos os testes realizados, as Figuras 10 e 11 mostram a comparação entre a deteç̧ão de mudanças utilizando todas as bandas multiespectrais, para a classe construção, e a deteç̧ão de mudanças utilizando apenas a banda $\mathrm{R}$ do sensor SPOT 6, que é a indicada, conforme Quadro 2. 
Figura 10 - Comparação dos parâmetros de qualidade entre o resultado final utilizando todas as bandas RGBNIR e somente a banda R, como sugerido no Quadro 2.

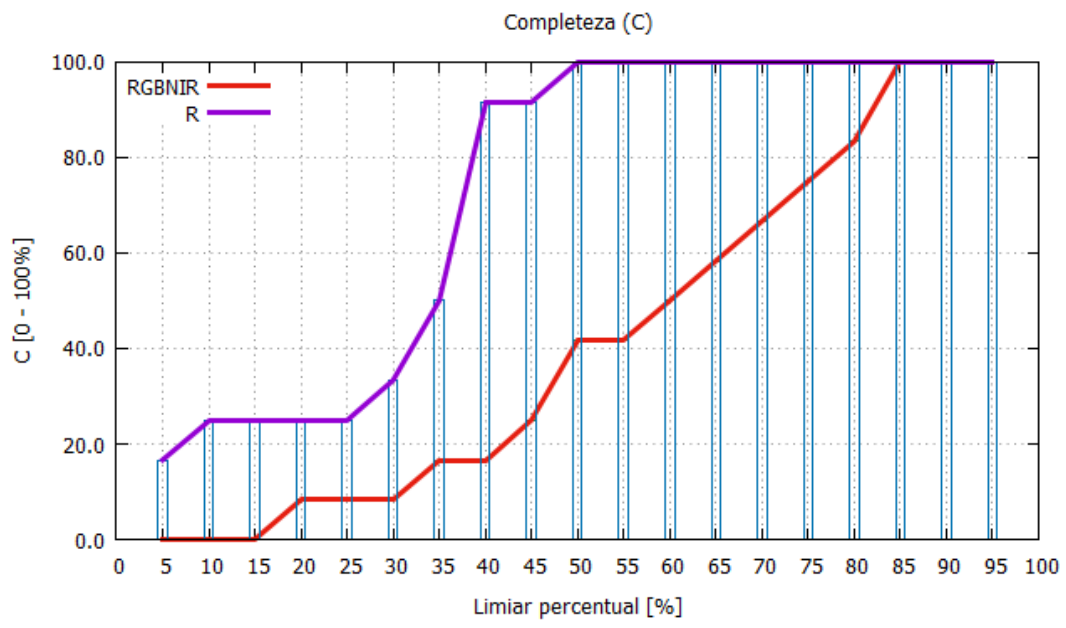

(a)

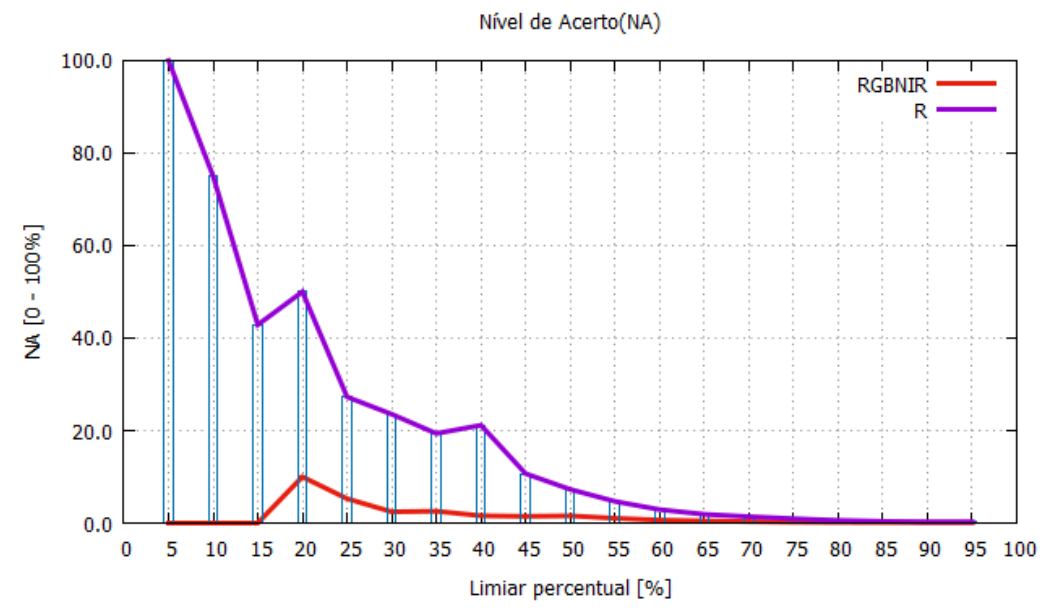

(b)

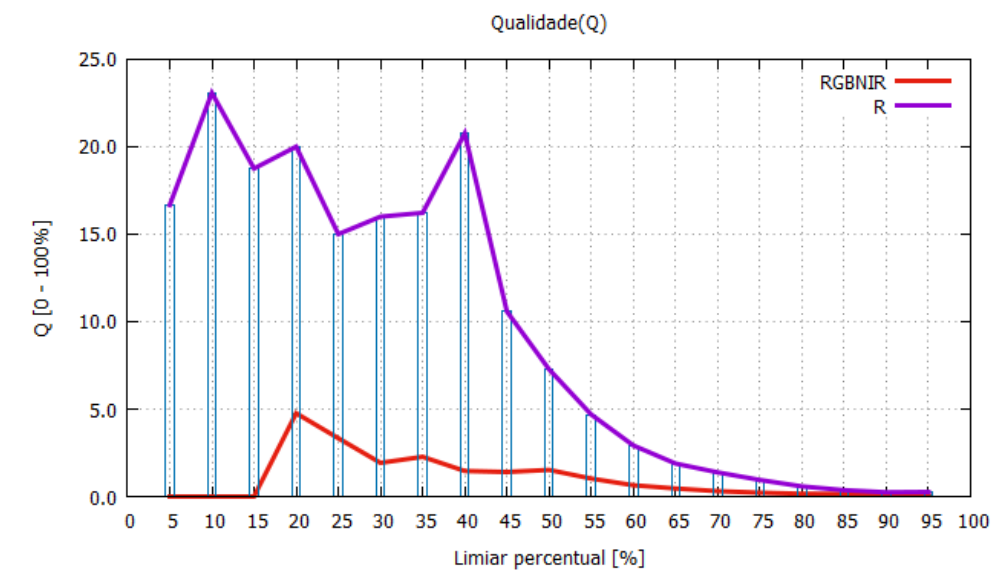

(c)

Fonte: Elaborada pelos autores.

Rev. Bras. de Cartografia, vol. 70, n. 4, outubro/dezembro, 2018. pp. 1348 - 1377. 
Figura 11 - Número de Falsos Positivos (a) e Falsos Negativos (b) para as bandas RGBNIR e para a banda $R$.

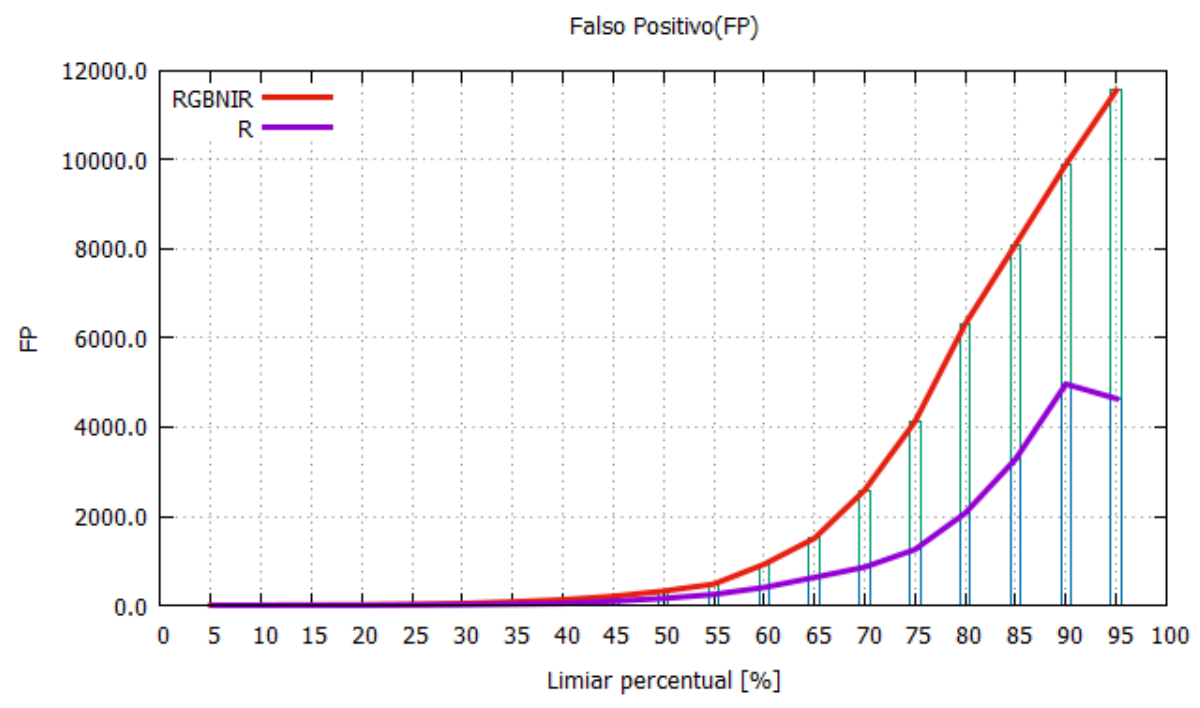

(a)

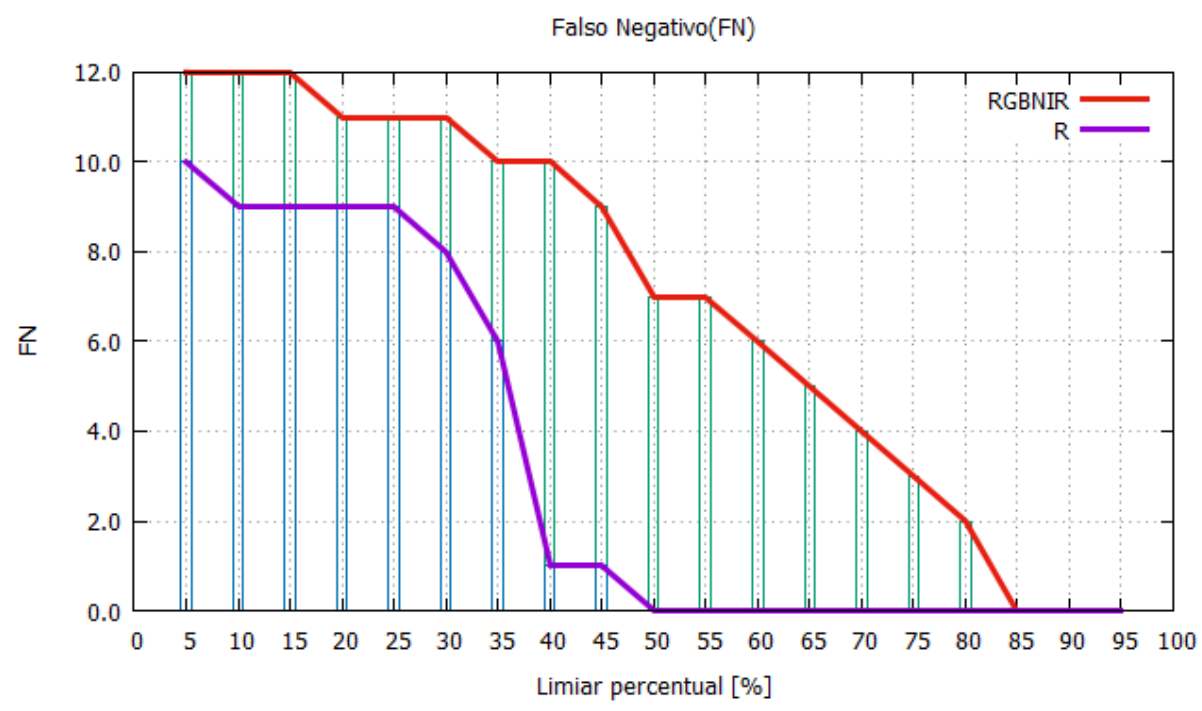

(b)

Fonte: Elaborada pelos autores.

Percebe-se de modo claro nos gráficos das Figuras 10 e 11, a melhora na detecção de mudanças quando utiliza-se a banda que forneceu a melhor resposta $(\mathrm{R})$, em relação ao uso de todas as bandas, como realizado em alguns trabalhos. A completeza, conforme Figura 10.a, atingiu o valor máximo para um limiar de 50\% ao utilizar apenas a banda R. No entanto, ao usar as bandas RGBNIR nota-se que a completeza atinge seu valor máximo apenas com um 
limiar de 85\%. Assim como a completeza, o nível de acerto (Figura 10.b) e consequentemente a qualidade (Figura 10.c), também indicam melhores resultados ao considerar a banda sugerida, ao invés da combinação de todas as bandas. O mesmo é válido para a quantidade de falsos positivos e falsos negativos (Figura 11), onde se percebe a redução de seus valores ao considerar a banda sugerida, tornando o método mais eficaz.

\section{Conclusões e Recomendações}

O método RCEN modificado, implementado neste trabalho, produz resultados adequados para uma análise automática de detecção de alterações, cujas análises podem ser verificados em (CALDEIRA, 2016). Este método é baseado no método RCEN proposto por Maldonado et al. (2007), onde algumas diferenças podem ser observadas: a determinação da direção do eixo de não mudança no método proposto é feita com base nos valores dos ND's tanto dos pixels que sofreram mudança quando dos que não sofreram mudança; e na métrica utilizada no RCEN modificado, que se baseia na dimensão do vetor determinado pelas projeções de um determinado pixel, sobre a linha de não mudança estimada. Neste método as imagens intermediárias obtidas para cada banda multiespectral geram informações que combinadas permitem a identificação de mudanças ao longo do tempo. A imagem de detecção final é criada a partir da combinação das imagens intermediárias produzidas pela combinação das bandas, ou apenas de uma banda, de cada uma das datas.

Baseados nos relatos das bibliografias consultadas e nos resultados apresentados pode-se considerar que o algoritmo é indicado para análises de detecção de cenas com períodos sazonais distintos, onde somente algumas áreas tenham sido alteradas, pois o mesmo não realçou pequenas mudanças sazonais da cobertura vegetal, mostrando a robustez do método proposto.

Inicialmente foram realizados experimentos com o uso simultâneo de todas as bandas disponíveis, podendo-se perceber alguns problemas, o que induziu a incorporar ao processo a redução da área de trabalho, limitado a 
apenas áreas de interesse; a análise da influência das bandas, em separado e combinadas, sendo feita a análise com base em indicadores de qualidade como completeza, nível de acerto e qualidade, além do número de falsos positivos e negativos. A partir das análises realizadas, para áreas distintas, com o predomínio de construção, corpo d'água, sombra, solo exposto e vegetação, foi possível definir as bandas e respectivos limiares, correspondentes aos melhores resultados, permitindo a automação do processo de detecção automática de mudanças.

Com base nos experimentos realizados utilizando dados do reservatório Canoas I, relativos a análise dos efeitos das bandas e combinações das bandas, recomenda-se realizar a deteç̧ão de mudanças por classes de objetos, sendo utilizadas bandas específicas e limiares específicos para cada uma delas. Estas bandas e limiares foram escolhidos de modo que seja reduzido o número de falsos positivos e falsos negativos, bem como o aumento da completeza e nível de acerto e, consequentemente, da qualidade. Entretanto, caso o usuário queira realizar todas as detecções de uma única vez, o recomendado é a deteç̧ão de mudanças em duas etapas. Na primeira etapa sugere-se realizar uma detecção utilizando uma máscara como filtro para o corpo D'Água, provindo do mapa do uso do solo, ou seja, realizar a detecção somente entre os corpos d'água e o limite da área de interesse. Na segunda etapa deve-se realizar a detecção de mudanças somente dentro do corpo D'Água. Esta sugestão é válida pelo fato de que a melhor banda para detecção de alterações no corpo D'Água é a banda do NIR, porém esta é a pior banda para as demais detecções, sendo assim a realização da detecção de mudanças em duas etapas será a melhor combinação. Deste modo, para as classes Construção, Sombras, Solo e Vegetação recomenda-se utilização da banda $\mathrm{R}$ com um limiar de 60\%, garantindo assim uma boa detecção em tais classes e para a deteç̧ão sob o corpo D'Água, remenda-se a utilização da banda NIR com um limiar de 80\%.

Como recomendações para trabalhos futuros, sugere-se um estudo específico para a minimização de detecção em sombras, para tornar o algoritmo um pouco mais robusto para a detecção de mudanças de forma 
automática no torno dos reservatórios. Adicionalmente, sugere-se realizara aplicação das bandas e limiares determinados, em outros reservatórios da mesma cascata, visando verificar a qualidade das alterações obtidas e a obtenção dos melhores parâmetros para a detecção de alterações de forma automática.

\section{Agradecimentos}

À empresa CTG Brasil (ex Duke Energy Brasil), pelo apoio, parceria e fomento; ao Conselho Nacional de Desenvolvimento Científico e Tecnológico $(\mathrm{CNPq})$, pelo suporte financeiro durante o desenvolvimento da pesquisa na forma de bolsa ao primeiro autor e ao Programa de Pós-Graduação em Ciências Cartográficas da Unesp/FCT. Adicionalmente os autores agradecem ao suporte e colaboração das seguintes profissionais e alunos: Eng. Ivan Takeshi Toyama (CTG Brasil); Thais Costa Dias, Wilson Estécio Marcílio Júnior, João Edezio Maiorchini da Rocha, André Luis Dias Andreotti, Nícolas Alvarenga, Maurício Campiteli, Natielly Marchioli, Jéssica Suyama e Léslie Stocco.

\section{Referências}

ARASATO, L. S.; SANTOS, J. R.; MALDONADO, F. D.; AMARAL, S.; RENNÓ, C. D. Deteç̧ão de mudança da paisagem a partir de análise multissensor e multitemporal em associação com variáveis geomorfométricas no domínio da floresta atlântica. Revista Brasileira de Cartografia, v. 64, n. 4, 2012, pp. 475-486.

ARASTOO, B.; GHAZARYAN, S. Land cover Changes Detection in Semnan province by Remote Sensing Techniques. International Journal of Agronomy and Plant Production, 4: 7, 2013, pp. 1637-1644.

CALDEIRA, C. R. T. Deteç̧ão de mudanças no entorno de reservatórios a partir de série temporal de imagens orbitais. 2016. Dissertação (Mestrado 
em Ciências Cartográficas) - FCT/Universidade Estadual Paulista, Presidente Prudente, 2016.

CALDEIRA, C. R. T; IMAI, N. N.;GALO, M. de L. B. T.; GALO, M.;HASEGAWA, J. K.; AMORIM, A.; PINTO, M. S. Desenvolvimento de Sistema de Monitoramento de Entorno dos Reservatórios Hidroelétricos - Diagnóstico e Definição de Parâmetros de Projeto. In: VIII CITENEL- Congresso de Inovação Tecnológica em Energia Elétrica, 2015, Costa do Sauipe/BA.

DEER, P. J. Digital change detection techniques: civilian and military applications. International Symposium on Spectral Sensing Research, 1995. Report (Greenbelt, MD: Goddard Space Flight Center), http://tpwww.gsfc.nasa.gov/ISSSR-95/digitalc.htm.

EHLERS, M.; SOFINA, N.; FILIPPOVISKA, Y.; KADA, M. Automated techniques for change detection using combined edge segment texture analysis, GIS, and 3D information. In: Q. WENG (Ed.), Global urban monitoring and assessment through Earth observation (pp. 325-351). CRC Press, Taylor \& Francis Group.

IMAI, N. N.; CALDEIRA, C. R. T.; GALO, M. de L. B. T.; GALO, M.; HASEGAWA, J. K.; AMORIM, A.; PINTO, M. S. Deteç̧ão de alterações em Áreas de Preservação Permanentes de reservatórios de UHE: primeiros experimentos na automatização do processo. In: Simpósio Brasileiro de Sensoriamento Remoto, 17. (SBSR), 2015, João Pessoa. Anais... São José dos Campos: INPE, 2015. Artigos, p. 2149-2156. Site: < http://www.dsr.inpe.br/sbsr2015/files/p0433.pdf>. Acessado em julho de 2015.

JENSEN, J. R.; COWEN, D.; NARUMALANI, S.; HALLS; J. Principles of change detection using digital remote sensor data. In: Integration of Geographic Information Systems and Remote Sensing, edited by J. L. Star, J. E. Estes, and K. C. McGwire (Cambridge: Cambridge University Press), pp. 37-54. 1997.

LU, D.; MAUSEL, P.; BRONDIZIO, E.; MORAN, E. F. Change Detection Techniques. International Journal of Remote Sensing. 25 (12):2365-2407. 2004

LU, D.; MAUSEL, P.; BRONDIZIO, E.; MORAN, E. F. Land-cover binary change detection methods for use in the moist tropical region of the Amazon: A 
comparative study. International Journal of Remote Sensing. 26:101. 2005.

MALDONADO, F. D.; SANTOS, J. R.; GRAÇA, P. M. L. Change detection technique based on the radiometric rotation controlled by no-change axis, applied on a semi-arid landscape. International Journal of Remote Sensing, v .28, n.8, 2007, pp.1001-1016.

TEWKESBURY, A. P.; COMBER, A. J.; TATE, N. J.; LAMB, A.; FISHER, P. F. A critical synthesis of remotely sensed optical image change detection techniques. Remote Sensing of Environment, 160, 2015, pp. 1-14.

WIEDEMANN, C.; HEIPKE, C.; MAYER, H.; JAMET, O. Empirical evaluation of automatically extracted road axes. Empirical Evaluation Methods in Computer Vision. IEEE Computer Society Press, 1998. pp 172-187. 